\title{
Correction to: New insights in gene expression alteration as effect of doxorubicin drug resistance in triple negative breast cancer cells
}

Cristina Alexandra Ciocan-Cartita ${ }^{1 \dagger}$, Ancuta Jurj $^{1 \dagger}$, Oana Zanoaga ${ }^{1}$, Roxana Cojocneanu ${ }^{1}$, Laura-Ancuta Pop ${ }^{1}$, Alin Moldovan', Cristian Moldovan², Alina Andreea Zimta², Lajos Raduly', Cecilia Pop-Bica', Mihail Buse², Liviuta Budisan', Piroska Virag ${ }^{3}$, Alexandru Irimie ${ }^{4,5}$, Sandra Martha Gomes Dias ${ }^{6}$, loana Berindan-Neagoe ${ }^{1,7^{*}}$ and Cornelia Braicu'

\section{Correction to: J Exp Clin Cancer Res 39, 241 (2020)} https://doi.org/10.1186/s13046-020-01736-2

Following publication of the original article [1], the authors identified an error in the author name of Sandra Martha Gomes Dias.

The incorrect author name is: Sandra Martha Gomez Diaz

The correct author name is: Sandra Martha Gomes Dias

The author group has been updated above, and the original article has been corrected. No further changes were made to the article.

\section{Author details}

${ }^{1}$ Research Center for Functional Genomics, Biomedicine and Translational Medicine, "Iuliu Hatieganu" University of Medicine and Pharmacy, Cluj-Napoca, Romania. ${ }^{2}$ MedFuture Research Center for Advanced Medicine, "Iuliu Hatieganu" University of Medicine and Pharmacy, Cluj-Napoca, Romania. ${ }^{3}$ Laboratory of Radiotherapy, Radiobiology and Tumor Biology, "Prof. Dr. Ion Chiricuta" Oncology Institute, Cluj-Napoca, Romania. ${ }^{4}$ Department of Surgical Oncology and Gynecological Oncology, "Iuliu Hatieganu" University of Medicine and Pharmacy, Cluj-Napoca, Romania. ${ }^{5}$ Department of Surgery, "Prof. Dr. Ion Chiricuta" Oncology Institute,

\footnotetext{
The original article can be found online at https://doi.org/10.1186/s13046020-01736-2.

* Correspondence: ioananeagoe29@gmail.com

${ }^{\dagger}$ Cristina Alexandra Ciocan-Cartita and Ancuta Jurj contributed equally to this work.

${ }^{1}$ Research Center for Functional Genomics, Biomedicine and Translational Medicine, "Iuliu Hatieganu" University of Medicine and Pharmacy, Cluj-Napoca, Romania

${ }^{7}$ Department of Functional Genomics and Experimental Pathology, "Prof. Dr. Ion Chiricuta" Oncology Institute, Cluj-Napoca, Romania
}

Cluj-Napoca, Romania. 'Brazilian Biosciences National Laboratory (LNBio), Brazilian Center for Research in Energy and Materials (CNPEM), Campinas, Sao Paulo, 13083-970, Brazil. ${ }^{7}$ Department of Functional Genomics and Experimental Pathology, "Prof. Dr. Ion Chiricuta” Oncology Institute,

Cluj-Napoca, Romania.

Published online: 17 December 2020

Reference

1. Ciocan-Cartita CA, et al. New insights in gene expression alteration as effect of doxorubicin drug resistance in triple negative breast cancer cells. J Exp Clin Cancer Res. 2020;39:241.

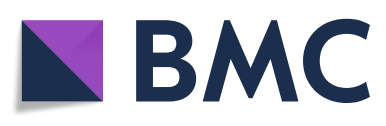

(0) The Author(s). 2020 Open Access This article is licensed under a Creative Commons Attribution 4.0 International License, which permits use, sharing, adaptation, distribution and reproduction in any medium or format, as long as you give appropriate credit to the original author(s) and the source, provide a link to the Creative Commons licence, and indicate if changes were made. The images or other third party material in this article are included in the article's Creative Commons licence, unless indicated otherwise in a credit line to the material. If material is not included in the article's Creative Commons licence and your intended use is not permitted by statutory regulation or exceeds the permitted use, you will need to obtain permission directly from the copyright holder. To view a copy of this licence, visit http://creativecommons.org/licenses/by/4.0/. The Creative Commons Public Domain Dedication waiver (http://creativecommons.org/publicdomain/zero/1.0/) applies to the data made available in this article, unless otherwise stated in a credit line to the data. 